\title{
PROBLEMAS DE EFECTIVIDAD DEL DERECHO DE LA UE. EL ÁREA DE LAS CLÁUSULAS ABUSIVAS COMO BANCO DE PRUEBAS
}

\author{
José Ramón Canedo Arrillaga
}

\begin{abstract}
SUMARIO: 1. INTRODUCCIÓN. 2. LA SAGA DE LAS ClÁUSULAS ABUSIVAS Y SU IMPACTO EN LA JURISPRUDENCIA ESPAÑOLA. 3. LOS PROBLEMAS PARA HACER EFECTIVO EL DERECHO DE LA UE FRENTE A LAS CLÁUSULAS ABUSIVAS. 4. CONCLUSIONES. BiBLIOGRAFÍA.
\end{abstract}

\section{INTRODUCCIÓN}

El sector del derecho de los consumidores y otros conexos han sufrido en tiempos recientes fuertes sacudidas cuyo origen está en el Derecho de la Unión Europea. Tanto la Sentencia de junio de 2012 dictada por el Tribunal de Justicia de la Unión Europea (en adelante, TJUE) en el asunto Banesto ${ }^{1}$, quizás menos «famosa», como la de marzo de 2013 dictada por el mismo Tribunal en el asunto $\mathrm{Aziz}^{2}$, han revolucionado partes muy relevantes de nuestro ordenamiento jurídico y, quizás, han servido para demostrar que las normas emitidas por la Unión Europea pueden tener su utilidad para algunos operadores jurídicos internos.

${ }^{1}$ Sentencia de la Sala Primera del Tribunal de Justicia de 14 de junio de 2012, asunto C-618/10, Banco Español de Crédito, S.A., ECLI:EU:C:2012:349. El texto de la misma se puede consultar en: $<$ http://curia.europa.eu/juris/document/document.jsf?text=\&docid $=12$ $3843 \&$ pageIndex $=0 \&$ doclang $=$ es \&mode $=1$ st \&dir $=\&$ occ $=$ first\&part $=1 \&$ cid $=510881>$ (última consulta: 30 de octubre de 2014).

2 Sentencia de la Sala Primera del Tribunal de Justicia de 14 de marzo de 2013, asunto C-415/11, Aziz, ECLI:EU:C:2013:164. El texto se puede consultar en: <http:// curia.europa.eu/juris/document/document.jsf?text $=\&$ docid $=135024 \&$ pageIndex $=0 \&$ do clang $=$ es $\&$ mode $=1$ st $\&$ dir $=\&$ occ $=$ first $\&$ part $=1 \&$ cid $=512405>$ (última consulta: 30 de octubre de 2014). 
Sin embargo, y pese al revuelo producido, la aplicación práctica de esa jurisprudencia que en algunos órganos judiciales se está llevando a cabo es cuando menos dudosa. Nos referimos en concreto a la cuestión de la posibilidad para el juez interno de, tras declarar una cláusula como abusiva, integrar el contrato modificando el contenido de dicha cláusula. Esta realidad nos sirve como disculpa para verificar que, en algunas situaciones, las normas del ordenamiento jurídico de la Unión Europea, aun cuando estén dotadas de primacía y de efecto directo, pueden revelarse incapaces de asegurar a sus pretendidos beneficiarios los derechos que intentan crear.

Nos encontraríamos así ante una debilidad consustancial a la naturaleza compleja de este ordenamiento en su relación con los ordenamientos internos, dificilmente subsanable en su etapa actual de desarrollo. No obstante, se apuntará alguna posibilidad, siquiera débil, de mejora de la situación, basada en la jurisprudencia del propio Tribunal de Justicia de la Unión Europea (TJUE).

\section{LA SAGA DE LAS CLÁUSULAS ABUSIVAS Y SU IMPACTO EN LA JURISPRUDENCIA ESPAÑOLA}

En este punto, la sentencia del TJUE que mejor nos permite empezar a abordar la cuestión es la ya citada del caso Banesto.

Recordemos brevemente los hechos del caso. Se trataba de un contrato de préstamo de $30.000 €$ para la adquisición de un vehículo suscrito en 2007 entre un consumidor y el Banco Español de Crédito. Entre las condiciones pactadas son relevantes a los efectos que nos ocupan las siguientes: interés retributivo del 7,950\%, TAE del 8,890 \% e interés de demora del $29 \%$. La fecha de vencimiento prevista era el 5 de junio de 2014. Antes de alcanzar la citada fecha, el consumidor incumplió su obligación de hacer frente al pago de alguna de las cuotas del préstamo, por lo que el Banco Español de Crédito optó por darlo por vencido anticipadamente y reclamó por vía judicial la cantidad de 29.381,95 euros, más intereses de demora y gastos ${ }^{3}$.

Tras una serie de vicisitudes procesales, el Juzgado de Primera Instancia n. ${ }^{\circ} 2$ de Sabadell llegó a la conclusión de que la cláusula sobre intereses de demora era abusiva y fijó el interés de demora en el 19\%. Recurrida tal resolución por la entidad bancaria ante la Audiencia Provincial de Barcelona, ésta decide formular cuestión prejudicial al TJUE a fin de aclarar, entre otras cosas y en lo que aquí nos afecta, qué alcance tiene el art. 6.1 de la Directiva 93/13/CEE, del Consejo, de 5 de abril de 1993, sobre las cláusulas abusivas en los contratos celebrados con consumidores.

${ }^{3}$ Para un comentario de esa sentencia desde una perspectiva diferente, puede verse Canedo Arrillaga, J. R.; Gordillo Pérez, L. I., «Tutela judicial, autonomía procedimental y efectividad del Derecho de la Unión», Revista General de Derecho Constitucional, n. ${ }^{\circ} 15,2012$, pág. 15 . 
Dicha disposición dicta que «(l)os Estados miembros establecerán que no vincularán al consumidor, en las condiciones estipuladas por sus Derechos nacionales, las cláusulas abusivas que figuren en un contrato celebrado entre éste y un profesional y dispondrán que el contrato siga siendo obligatorio para las partes en los mismos términos, si éste puede subsistir sin las cláusulas abusivas $\rangle^{4}$. La pregunta remitida por la Audiencia Provincial ponía en relación esta disposición de la Directiva con el art. 83 del Real Decreto Legislativo $1 / 2007$, de 16 de noviembre, por el que se aprueba el texto refundido de la Ley General para la Defensa de los Consumidores y Usuarios y otras leyes complementarias. Como es bien sabido, este precepto interno, tras declarar que las cláusulas abusivas serán nulas de pleno derecho y se tendrán por no puestas, impone al juez la obligación de integración del contrato y de moderar los derechos y obligaciones de las partes contenidas en el mismo.

El punto de partida adoptado por el TJUE para abordar esta cuestión es la consideración general de esa Directiva de protección de consumidores. La citada norma asume que, en este tipo de contratos, el consumidor se encuentra en una posición de desventaja frente al profesional, entendiendo por tal toda persona física o jurídica que, en las transacciones reguladas por la Directiva, actúe dentro del marco de su actividad profesional, ya sea pública o privada (art. 1). Tal situación de inicio supone para el consumidor la incapacidad para negociar el contenido de algunas cláusulas contractuales, situación de hecho que se pretende paliar gracias al art. 6.1 de la citada Directiva, al que ya nos hemos referido, que obliga a los Estados miembros a que, en sus ordenamientos jurídicos, se prevea de manera imperativa que las cláusulas abusivas no vinculen a los consumidores. La consecuencia natural será, obviamente, le necesidad de una intervención judicial activa en favor del consumidor cuando se dan las circunstancias de hecho oportunas ${ }^{5}$. El juez

${ }^{4}$ Enlasentenciade30deabrilde2014, enelasuntoC-26/13,Kásler,ECLI:EU:C:2014:282, todavía no publicada, se entiende que un contrato de préstamo hipotecario denominado en divisas no puede subsistir si se considera abusiva una cláusula que faculte al banco para calcular las cuotas mensuales de devolución vencidas sobre la base de la cotización de venta de la divisa, mientras que el importe del préstamo entregado se fijó en función de la cotización de compra que aplica para esa divisa. En estas circunstancias, el TJUE entiende que la Directiva no se opone a una normativa nacional que permite al juez nacional subsanar la nulidad de esa cláusula sustituyéndola por una disposición supletoria del Derecho nacional. El texto se puede consultar aquí: $<$ http://curia.europa.eu/juris/document/document.jsf?text=\&docid=15 1524\&pageIndex $=0 \&$ doclang $=$ es \&mode $=1$ st $\&$ dir $=\&$ occ $=$ first $\&$ part $=1 \&$ cid $=291709>$ (última consulta: 30 de octubre de 2014).

5 Sentencias Banesto, citada en la nota 1, apartado 40; de 26 de octubre de 2006, Mostaza Claro, C-168/05, Rec. p. I-10421, ECLI:EU:C:2006:675, apartado 36; de 6 de octubre de 2009, Asturcom Telecomunicaciones, C-40/08, Rec. p. I-09579, ECLI:EU:C:2009:615, apartado 30; de 9 de noviembre de 2010, VB Pénzügyi Lízing, C-137/08, Rec. p. I-10847, ECLI:EU:C:2010:659, apartado 47, y de 15 de marzo de 
interno tendrá que declarar, incluso de oficio, si una cláusula incluida en ese tipo de contratos es abusiva y, en su caso, deberá extraer las consecuencias, haciéndola inaplicable, salvo que el consumidor se oponga a ello ${ }^{6,7}$.

En su sentencia comentada, el TJUE, tras declarar contraria a la Directiva la normativa procesal española que no permitía al juez que conoce de una demanda en un procedimiento monitorio examinar de oficio -in limine litis ni en ninguna fase del procedimiento- el carácter abusivo de una cláusula sobre intereses de demora contenida en un contrato celebrado entre un profesional y un consumidor, declara así mismo contrario a la norma europea el mencionado artículo 83 del Real Decreto Legislativo 1/2007 en la medida en que «atribuye al juez nacional, cuando éste declara la nulidad de una cláusula abusiva contenida en un contrato celebrado entre un profesional y un consumidor, la facultad de integrar dicho contrato modificando el contenido de la cláusula abusiva». Tal y como recuerda el Tribunal (apartado 68), la Directiva impone a los Estados miembros la obligación de prever medios adecuados y eficaces «para que cese el uso de cláusulas abusivas en los contratos celebrados entre profesionales y consumidores» (art. 7). Así las cosas, «si el juez nacional tuviera la facultad de modificar el contenido de las cláusulas abusivas que figuran en tales contratos, dicha facultad podría poner en peligro la consecución del objetivo a largo plazo previsto en el artículo 7 de la Directiva 93/13» dado que esto «contribuiría a eliminar el efecto disuasorio que ejerce sobre los profesionales el hecho de que, pura y simplemente, tales cláusulas abusivas no se apliquen frente a los consumidores (...) en la medida en que los profesionales podrían verse tentados a utilizar cláusulas abusivas al saber que, aun cuando llegara a declararse la nulidad de las mismas, el contrato podría ser integrado por el juez nacional en lo que fuera necesario, garantizando de este modo el interés de dichos profesionales» (apartado 69) y no ofreciendo a los consumidores una protección tan eficaz como la resultante de la no aplicación de las cláusulas abusivas.

Con posterioridad y como ya se ha dicho, el TJUE dictó una nueva sentencia relacionada con nuestro ordenamiento jurídico y la protección de consumidores en el asunto Aziz y como resultado de ésta, el legislador español decidió llevar a cabo una reforma del ordenamiento jurídico con vistas a

2012, Pereničová y Perenič, C-453/10, ECLI:EU:C:2012:144, apartado 28 (publicada en la Rec. electrónica).

6 Sentencias Banesto, antes citada, apartado 42; Mostaza Claro, antes citada, apartado 38; de 4 de junio de 2009, Pannon GSM, C-243/08, Rec. p. I-4713, apartado 31; Asturcom Telecomunicaciones, antes citada, apartado 32, y VB Pénzügyi Lízing, antes citada, apartado 49.

7 Sobre la posibilidad de que el consumidor se oponga a la inaplicación, véase la Sentencia Pannon, antes citada, apartado 33. 
«reforzar la protección a los deudores hipotecarios» ${ }^{8}$. De entre los varios aspectos cubiertos por esta Ley, destacamos a los efectos de este artículo la previsión contenida en el art. 3, en virtud de la cual se modifica el art. 114 de la Ley Hipotecaria, añadiéndole un tercer párrafo a fin de limitar los intereses de demora de préstamos o créditos para la adquisición de vivienda habitual garantizados con hipoteca sobre la misma vivienda a un máximo de tres veces el interés legal del dinero. Por su parte, la Disposición Transitoria Segunda de la Ley 1/2013 dispone, a los efectos que aquí nos ocupan, que la limitación antedicha de intereses es aplicable a los procedimientos de ejecución o venta extrajudicial iniciados y no concluidos antes del 15 de mayo de 2013, así como a los procedimientos en los que se haya fijado ya la cantidad por la que se solicita que se despache ejecución o la venta extrajudicial.

En relación con la cuestión que analizamos, los Tribunales españoles han adoptado resoluciones sustancialmente divergentes.

Se ha decantado una línea jurisprudencial que, tras la consideración de abusiva de una cláusula de intereses moratorios excesivamente altos, opta por declararla nula y, como consecuencia, exonera al consumidor del pago de esos intereses. Ejemplo de esta línea sería la sentencia de la sección $8{ }^{a}$ de la Audiencia Provincial de Valencia de 8 de julio de 2013, n. ${ }^{\circ} 316 / 2013$, en la que dicha sección rectifica el criterio del juzgador de instancia, que había recalculado los intereses moratorios, y opta por dejar sin efecto el pronunciamiento de dicha resolución en lo tocante a la condena al pago de intereses moratorios. Al mismo resultado llegó por su parte la sección 2. a de la Audiencia Provincial de Lleida, en sentencia de 17 de octubre de 2013, n. ${ }^{\circ}$ 390/2013.

En el mismo sentido, el Juzgado de Primera Instancia n. ${ }^{\circ}$ 38, Barcelona, en Auto de 1 octubre de 2013, n. ${ }^{\circ}$ 268/2013, optó por seguir la ejecución de un préstamo hipotecario si bien sin aplicación de intereses moratorios. En este caso el juzgador argumenta la imposibilidad de moderar tales intereses o incluso de aplicar los intereses legales desde la reclamación judicial, tanto por el hecho de que la parte interesada no lo solicitó «como por el sentido de exclusión de la sentencia del TJUE de 14 de junio de 2012 y los argumentos aducidos».

En otra línea, algunas resoluciones judiciales han optado por declarar nula una cláusula de intereses moratorios por considerarla abusiva pero han decidido integrar el contrato fijando un tipo de interés no abusivo. La Sección

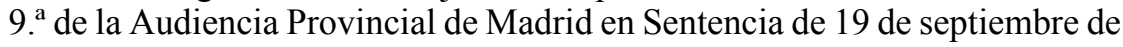
2013, n. ${ }^{\circ} 386 / 2013$, ratifica la dictada por el Juzgado de $1 .^{\mathrm{a}}$ Instancia n. $^{\circ} 3 \mathrm{de}$ Madrid en la que éste estableció como interés moratorio a pagar en 2,5 veces el interés legal del dinero (inspirándose en las previsiones contenidas en la

${ }^{8}$ Ley $1 / 2013$, de 14 de mayo, de medidas para reforzar la protección a los deudores hipotecarios, reestructuración de la deuda y alquiler social, BOE 116/2013, de 15 de mayo de 2013. 
Ley 7/1995, de 23 de marzo, de crédito al consumo). En el mismo sentido se pronunció el Juzgado de Primera Instancia n. ${ }^{\circ} 12$ de Valladolid, en su auto de 24 de abril de 2013, procd. n. ${ }^{\circ}$ 486/2011.

Finalmente, otra línea jurisprudencial se ha decantado, tras fundamentar el carácter abusivo de determinadas cláusulas de intereses moratorios, por entender que, no obstante, procede considerar que el principal devenga como interés de demora únicamente el interés legal del dinero, sobre la base del art. 1108 del Código Civil. El razonamiento es que, tras declarar nula la cláusula contractual, es aplicable la citada disposición, dada la falta de pacto sobre ese punto. En este sentido se han pronunciado, por ejemplo, la sección 1. a de la Audiencia Provincial de Pontevedra, en sentencia de 24 de septiembre de

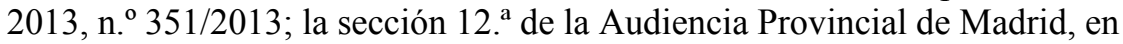
sentencia de 16 de julio de 2014, n. ${ }^{\circ} 387 / 2014$; la sección 14. ${ }^{a}$ de la Audiencia Provincial de Barcelona, en sentencia de 26 de junio de 2014, n. $^{\circ}$ 248/2014; la sección 2. ${ }^{a}$ de la Audiencia Provincial de Cádiz, en sentencia de 22 de julio de 2014, n. ${ }^{\circ}$ 176/2014; la sección 13. a de la Audiencia Provincial de Barcelona, en sentencia de 1 de septiembre de 1014, n. ${ }^{\circ}$ 405/2014; la sección 11. ${ }^{a}$ de la Audiencia Provincial de Madrid, en sentencia de 24 de julio de 2014, n. . 276/2014.

En fechas recientes, se ha añadido un elemento más al paisaje que analizamos, relevante para la tesis del artículo. Nos referimos a las conclusiones presentadas el 16 de octubre de 2014 por el Abogado General Wahl en los asuntos acumulados C-482/13, C-484/13, C-485/13 y C-487/13, Unicaja Banco y Caixabank $k^{9}$ Las mismas se encuadran en diversas peticiones de interpretación de la Directiva 93/13 formuladas por el Juzgado de Primera Instancia e Instrucción $n .^{\circ} 2$ de Marchena (Sevilla). Pese a que las preguntas planteadas son cuatro, el Abogado General las reconduce a dos.

Por un lado, estudia si la Directiva 93/13, y en particular su artículo 6, apartado 1, obliga al juez interno a eliminar una cláusula contractual que establece el interés de demora considerado abusivo o si, por el contrario, el juzgador debe moderar el tipo de interés o admitir tal moderación por parte de la entidad bancaria.

A este respecto, el Abogado General entiende, junto con el juzgador nacional, que la cuestión ya ha sido resuelta por el TJUE con anterioridad, en concreto en las sentencias Banco Español de Crédito, ya citada, y Asbeek

${ }^{9}$ Conclusiones del Abogado General Wahl de 16 de octubre de 2014, asuntos acumulados C-482/13, C-484/13, C-485/13 y C-487/13, Unicaja Banco y Caixabank, ECLI:EU:C:2014:2299, todavía no publicadas. El texto se puede consultar aquí: <http:// curia.europa.eu/juris/document/document.jsf?text $=\&$ docid $=158644 \&$ pageIndex $=0 \&$ docl ang $=$ es $\&$ mode $=1$ st \&dir $=\& o c c=$ first $\&$ part $=1 \&$ cid $=291709>$ (última consulta: 30 de octubre de 2014). 
Brusse y Man Garabito ${ }^{10}$. Así, afirma lo ya evidente: por un lado, que el juez nacional debe declarar nula la cláusula que considere abusiva; y, por otro y en relación con las cláusulas penales, que «el artículo 6, apartado 1, de la Directiva 93/13 no puede interpretarse en el sentido de que permita al juez nacional, cuando aprecie el carácter abusivo de una cláusula penal en un contrato celebrado entre un profesional y un consumidor, reducir el importe de la pena contractual impuesta al consumidor, en lugar de excluir plenamente la aplicación frente a éste de la referida cláusula» ${ }^{11}$.

La segunda cuestión prejudicial gira en torno a la compatibilidad de la Disposición Transitoria Segunda de la Ley 1/2013 con la Directiva 93/13. En concreto, el Abogado General estudia si, «en procedimientos de ejecución hipotecaria, el acreedor que exige el pago de intereses de demora en virtud de una cláusula contractual que establece tales intereses a un tipo superior al máximo legal (tres veces el interés legal del dinero) puede recalcular el tipo de los intereses de demora de forma que no exceda de ese límite».

El Abogado General analiza el sentido de la citada Disposición Adicional Segunda de la Ley 1/2013 a la luz de las aclaraciones aportadas por el Gobierno español en el acto de la vista. Según Wahl, tal disposición no obliga al juez nacional a moderar el tipo de los intereses de demora contenidos en cláusulas consideradas abusivas. Por un lado, la Disposición Transitoria no sólo se aplica a cláusulas contenidas en contratos que se encuentran dentro del ámbito de aplicación de la Directiva 93/13 (por ejemplo, porque las cláusulas han sido negociadas individualmente o porque han sido redactadas de manera clara y comprensible). Por otro lado, y siempre según el criterio del Gobierno español, el objetivo tanto del nuevo apartado 3 incluido en el art. 144 de la Ley Hipotecaria como de la referida Disposición Transitoria Segunda de la Ley 1/2013 es «limitar la cantidad máxima garantizada con el bien hipotecado para limitar el alcance de las obligaciones contractuales exigibles a través de la garantía hipotecaria respecto de terceros», cuando nos encontremos ante préstamos garantizados con hipotecas constituidas sobre la vivienda habitual del deudor.

Ante esa interpretación, el Abogado General se plantea la posibilidad, sugerida (pero no fundamentada) por el Juzgado de Marchena, de si ese límite máximo en los intereses moratorios al que se refieren las disposiciones citadas puede jugar a la hora de decidir si unos intereses concretos son o no

${ }^{10}$ Sentencia del Tribunal de Justicia (Sala Primera) de 30 de mayo de 2013, asunto C-488/11, Asbeek Brusse y de Man Garabito, ECLI:EU:C:2013:341, todavía no publicada. El texto se puede consultar aquí: $<$ http://curia.europa.eu/juris/document/document.jsf ?text $=\&$ docid $=137830 \&$ pageIndex $=0 \&$ doclang $=$ es \&mode $=1$ st $\&$ dir $=\&$ occ $=$ first \&part $=1$ $\&$ cid=291709 $>$ (última consulta: 30 de octubre de 2014).

11 Apartado 27 de las Conclusiones, en el que se cita el apartado 59 de la sentencia Asbeek Brusse y Man Garabito, ya citada en la nota anterior. 
abusivos. Ante tal posibilidad, Wahl entiende que «no es posible extraer la consecuencia de que cualquier tipo contractual superior a ese límite sea automáticamente abusivo con arreglo a la Directiva o que cualquier tipo inferior a dicho límite automáticamente no lo sea. No existe un criterio infalible que permita apreciar automáticamente si una cláusula de intereses moratorios es abusiva», a lo que añade que «(r)esulta evidente que la mera comparación de una cláusula de intereses moratorios con un múltiplo del interés legal del dinero es absolutamente insuficiente para adoptar una posición fundada acerca de su carácter abusivo», análisis que debería basarse en el importe y en la duración del préstamo. Finalmente, dichas conclusiones se cierran con un apartado 46 en el que se afirma literalmente que, en el caso de que el órgano jurisdiccional remitente se incline por considerar que los tipos de los intereses moratorios de los préstamos hipotecarios en cuestión son efectivamente abusivos, «de mi respuesta a la primera cuestión, antes expuesta, se desprende que el órgano jurisdiccional remitente debe garantizar que los consumidores no se encuentren vinculados por esas cláusulas sin que sea posible moderar el propio tipo o sustituirlo por un tipo establecido por la legislación española».

\section{LOS PROBLEMAS PARA HACER EFECTIVO EL DERECHO DE LA UE FRENTE A LAS CLÁUSULAS ABUSIVAS}

Nuestro análisis de los problemas de efectividad real del Derecho de la Unión Europea va a tomar como punto de partida las resoluciones de los tribunales españoles en las que se opta por la fijación de unos intereses a pagar por el consumidor, sean los fijados en la propia resolución moderando los del contrato, sean lo que derivan de la aplicación del art. 1108 del Código Civil. Vaya por delante que, a nuestro entender, la primera de la opciones no se sostiene a la luz del conjunto de la jurisprudencia del TJUE sobre la Directiva $93 / 13$.

No obstante, es perfectamente posible que incluso la segunda opción sea inviable. Recordemos que, en la base de la jurisprudencia sobre el art. 6 de la Directiva 93/13, está la consideración de que la finalidad de la misma es la protección que se pretende garantizar a los consumidores. Este interés público obliga a los Estados, en virtud del art. 7 de la Directiva, a prever medios adecuados y eficaces «para que cese el uso de cláusulas abusivas en los contratos celebrados entre profesionales y consumidores». Estas bases llevan a Tribunal a afirmar que «si el juez nacional tuviera la facultad de modificar el contenido de las cláusulas abusivas que figuran en tales contratos, dicha facultad podría poner en peligro la consecución del objetivo a largo plazo previsto en el artículo 7 de la Directiva ya que la mencionada facultad debilitaría el efecto disuasorio que ejerce sobre los profesionales el hecho de que, pura y simplemente, tales cláusulas abusivas 
no se apliquen frente a los consumidores» ${ }^{12}$ (sentencia Banco Español de Crédito, ya citada, apartados 66 a 69).

$\mathrm{Si}$, como hacen algunas sentencias citadas, tras declarar la nulidad de la cláusula de intereses moratorios, se aplica el art. 1108 CC, se estaría beneficiando en cierta medida a quien ha incluido la cláusula abusiva en el contrato. Por decirlo de otro modo, la entidad crediticia no tendría tanto que perder al incluir este tipo de cláusulas si, finalmente, se le conceden unos intereses como los recogidos en el art. $1108 \mathrm{CC}$. No estamos defendiendo la incompatibilidad genérica de dicha disposición con la jurisprudencia de Luxemburgo, sino lo inadecuado de su aplicación a este tipo de situaciones, dado que al hacerlo se debilitaría el efecto disuasorio que se pretende ejercer sobre los profesionales. Recordemos, por otro lado, la afirmación del Abogado General Wahl: «sin que sea posible moderar el propio tipo o sustituirlo por un tipo establecido por la legislación española». Esta última referencia, aunque pensada para la Ley 1/2013, podría ser aplicable así mismo al art. $1108 \mathrm{CC}$.

Esta interpretación vendría apoyada de igual modo por la especial consideración que el TJUE da a las disposiciones de esta Directiva. En efecto, tanto en la sentencia Asbeek Brusse y de Man Garabito (apartado 38) como la dictada en el asunto Banesto (apartado 40) o la sentencia Banif Plus Bank (apartado 20) ${ }^{13}$, el TJUE ha declarado el art. 6.1 como norma imperativa, a lo que ha añadido que «dada la naturaleza y la importancia del interés público en que se basa la protección que la Directiva otorga a los consumidores, el artículo 6 de dicha Directiva debe considerarse una norma equivalente a las disposiciones nacionales que, en el ordenamiento jurídico interno, tienen rango de normas de orden público (véanse la sentencia de 6 de octubre de 2009, Asturcom Telecomunicaciones, C-40/08, Rec. p. I-9579, apartado 52, y el auto de 16 de noviembre de 2010, Pohotovost', C-76/10, Rec. p I-11557, apartado 50). Debe considerarse que esa calificación se extiende a todas las disposiciones de la Directiva que sean indispensables para la realización del objetivo pretendido por el citado artículo 6$\rangle^{14}$.

A efectos argumentativos, vamos a imaginar que tal condena al pago de intereses es considerada por el TJUE como contraria a la Directiva 93/13, sea en la sentencia que dicte en el caso Unicaja Banco y Caixabank -supuesto poco probable- o en cualquiera posterior.

12 Sentencia Asbeek Brusse y de Man Garabito, apartado 58; o sentencia Banesto, apartados 66 a 69 .

13 Sentencia del Tribunal de 21 de febrero de 2013, asunto C-472/11, Banif Plus Bank, ECLI:EU:C:2013:88, todavía no publicada. El texto se puede consultar aquí: $<$ http://curia.europa.eu/juris/document/document.jsf?text=\&docid=134101\&pageIndex $=$ $0 \&$ doclang $=$ es $\&$ mode $=1$ st $\&$ dir $=\&$ occ $=$ first $\&$ part $=1 \&$ cid $=291709>$ (última consulta: 30 de octubre de 2014).

14 Sentencia Asbeek Brusse y de Man Garabito, apartado 44. 
Partiendo de ese supuesto, vamos a considerar las posibles vías jurídicas de las que dispondrían aquellos consumidores condenados a esos pagos de intereses. Obviamente, si la sentencia condenatoria está en plazo para ser recurrida o el recurso está pendiente de resolución, la nueva jurisprudencia que pudiera sentar la jurisdicción de Luxemburgo desplegaría todos sus efectos en su favor. Recordemos que las sentencias dictadas por el TJUE como resultado de una cuestión prejudicial no sólo vinculan al órgano jurisdiccional que la planteó, sino a los que pudieran conocer del mismo asunto por vía de recurso o a cualquier otro órgano jurisdiccional de un Estado miembro de la Unión Europea ${ }^{15}$.

En caso de que la sentencia del tribunal interno fuese o hubiese devenido firme, los problemas a los que debería enfrentarse el consumidor crecen exponencialmente. Es bien sabido que no resulta factible formular recurso de revisión de sentencias definitivas en un supuesto como el que nos ocupa. En consecuencia, el citado consumidor tendría ante sí la posibilidad de formular una reclamación por responsabilidad extracontractual contra el Estado por incumplimiento de Derecho de la UE. El incumplimiento es potencialmente doble. Por un lado, podría existir si el tribunal sentenciador no formuló cuestión prejudicial pese a adoptar resoluciones no susceptibles de recurso en Derecho interno (art. 234 TFUE). Para que tal opción exista, es necesario que ante el juez interno se hayan suscitado dudas sobre la interpretación en este caso de la Directiva 93/13. Recordemos en este punto que si un órgano jurisdiccional interno, estando obligado a hacerlo en virtud del párrafo tercero del art. 267 TFUE, no formula la oportuna cuestión prejudicial y no justifica por qué no lo hace, estaría infringiendo el art. 6 del Convenio Europeo para la Protección de los Derechos Humanos y de las Libertades Fundamentales, tal y como ha sentenciado recientemente el Tribunal Europeo de Derechos Humanos en su sentencia Dhahbi c. Italia ${ }^{16}$.

15 Por todas, véase la sentencia del Tribunal de 30 de marzo de 2006, asunto C-184/04, Uudenkaupungin kaupunki, ECLI:EU:C:2006:214, Rec. p. 3039, en cuyo apartado 53 puede leerse: «Conforme a reiterada jurisprudencia, la interpretación que, en el ejercicio de la competencia que le confiere el artículo $234 \mathrm{CE}$, haga el Tribunal de Justicia de una norma de Derecho comunitario aclara y precisa, cuando sea necesario, el significado y el alcance de dicha norma, tal como debe o habría debido ser entendida y aplicada desde el momento de su entrada en vigor. De ello resulta que la norma que haya sido interpretada por este Tribunal puede y debe ser aplicada por el juez incluso a relaciones jurídicas nacidas y constituidas antes de la sentencia que resuelva sobre la petición de interpretación, si además se reúnen los requisitos que permiten someter a los órganos jurisdiccionales competentes un litigio relativo a la aplicación de dicha norma».

${ }_{16}$ Sentencia de 8 de abril de 2014, 17120/09. Su texto puede consultarse aquí: $<$ http:// hudoc.echr.coe.int/sites/eng/pages/search.aspx?i=001-142504> (última consulta: 30 de octubre de 2014). En ese caso, el TEDH considera que hay violación del art. 6 del Convenio (derecho a un proceso equitativo) en la medida en que la Corte de Casación italiana no 
Así mismo sería posible la reclamación al entender que incumplimiento deriva de una interpretación errónea de la Directiva 93/13 al conceder intereses moratorios en contra de lo dispuesto en el art. 6 de la misma, interpretado a la luz del objetivo general de la norma. No es impedimento para esta reclamación el hecho de que la sentencia del TJUE que establezca la inaplicabilidad del art. $1108 \mathrm{CC}$-siempre en el supuesto de que se dicte tal resoluciónse haya dictado con posterioridad a la interna. Como es bien sabido, el TJUE, cuando dicta sentencia en respuesta a una cuestión prejudicial en interpretación de una norma UE, ofrece la interpretación con efectos ex tunc, es decir, la interpretación que debía haberse dado a la misma desde el momento en que se adoptó y por lo tanto con efecto retroactivo pleno ${ }^{17}$.

El régimen jurídico de tal reclamación lo encontraríamos en la sentencia Brasserie de pêcheur y Factortame III ${ }^{18}$. Para que un particular tenga derecho a indemnización por los daños sufridos como consecuencia del incumplimiento estatal es necesario que la norma infringida tuviese como objetivo crear derechos para los particulares. Tal requisito no ofrece problemas en nuestro caso. La segunda condición consiste en que la violación sea suficientemente caracterizada, determinación que deberá hacer el juez nacional tomando en consideración, entre otros, el grado de claridad y precisión de la norma vulnerada, la amplitud del margen de apreciación que la misma conceda a los Estados, el carácter intencional o involuntario de un eventual error de Derecho, su carácter excusable o inexcusable o el hecho de que el comportamiento adoptado por las instituciones de la UE hayan podido contribuir a la omisión, la adopción o al mantenimiento de medidas o prácticas nacionales contrarias al Derecho de la UE. Finalmente, el juez interno deberá constatar la existencia de un nexo de causalidad entre el incumplimiento y el daño causado ${ }^{19}$.

Ahora bien, siendo cierto que esa vía jurídica existe, y dejando al margen los problemas que puedan derivar por ejemplo del costo de este proceso para alguien que, por definición, no se encuentra en buena situación económica pero que, disponiendo de una vivienda pudiera no tener acceso al beneficio de justicia gratuita-, no lo es menos que las reclamaciones de daños y perjui-

se ampara en la excepción del acto claro para no formular la cuestión prejudicial sino que simplemente opta por no formularla sin justificación alguna. La posibilidad ya se había apuntado en la sentencia Vergauwen en 2012, pero en aquel supuesto no se entendió que había habido violación del Convenio. Sentencia Vergauwen y otros c. Bélgica, de 10 de abril de 2012, 4832/04. Su texto puede consultarse aquí: <http://hudoc.echr.coe.int/sites/ eng/pages/search.aspx?i=001-110889> (última consulta: 30 de octubre de 2014).

${ }_{17}$ Ver por todas la sentencia Uudenkaupungin kaupunki, citada en la nota 15.

18 Sentencia del Tribunal de 5 de marzo de 1996, asuntos acumulados C-46/93 y C-48/93, ECLI:EU:C:1996:79, Rec. p. 1029.

19 Apartados 51 y 56, esencialmente. 
cios contra el Estado por incumplimiento de Derecho de la UE cuando quien ha incumplido es un tribunal de justicia resultan ciertamente difíciles.

Recordemos que el TJUE ha aceptado como principio que tal circunstancia pueda darse. Así, en la sentencia Köbler ${ }^{20}$, el Tribunal afirma que «el principio según el cual los Estados miembros están obligados a reparar los daños causados a los particulares por violaciones del Derecho comunitario que les sean imputables también se aplica cuando la violación de que se trate se derive de una resolución de un órgano jurisdiccional que resuelva en última instancia», si se dan las condiciones reseñadas de Brasserie du pêcheur. No obstante, el propio Tribunal dispone así mismo que «para determinar si la violación está suficientemente caracterizada cuando se derive de una resolución de ese tipo, el juez nacional competente debe examinar, habida cuenta de la especificidad de la función jurisdiccional, si dicha violación presenta un carácter manifiesto», circunstancia que se daría si se tratase de una resolución dictada con un desconocimiento manifiesto de la jurisprudencia del Tribunal de Justicia en la materia. La posibilidad y sus limitaciones se vieron corroboradas posteriormente en la sentencia Traghetti del Mediterraneo ${ }^{21}$.

\section{CONCLUSIONES}

Como hemos podido ver, ante resoluciones judiciales que pudieran estar aplicando una interpretación errónea de la jurisprudencia europea sobre las cláusulas abusivas en contra del consumidor, las vías jurídicas al alcance de éste pueden tener una viabilidad escasa, dada la debilidad que se presume a ese consumidor tanto frente a las entidades crediticias con ante unos tribunales internos que, ante distintas posibles interpretaciones de la norma europea, optan por una de ellas sin plantear la oportuna cuestión prejudicial ante el TJUE. Esta actitud es tanto más sorprendente cuanto que hemos podido asistir en tiempos recientes a un revolcón judicial de enjundia por parte del Tribunal de Luxemburgo en cuanto a buena parte de las normas procesales que rigen tanto el procedimiento monitorio como las ejecuciones de créditos hipotecarios. Y frente a esa realidad de cambios muy sustantivos e inesperados provocados por la jurisprudencia europea, muchos jueces internos, con muy honrosas excepciones, optan por la vía autista de no consultar al máximo intérprete de las normas de la Unión, con los consiguientes daños que esto pudiera irrogar a los consumidores.

Si bien en un contexto diferente y con un trasfondo teórico distinto, otro ejemplo de escasa efectividad real de las normas de la Unión Europea nos lo

${ }^{20}$ Sentencia del Tribunal de 30 de septiembre de 2003, asunto C- 224/01, Köbler, ECLI:EU:C:2003:513, Rec. p. 10239.

${ }^{21}$ Sentencia del Tribunal de 13 de junio de 2006, asunto C-173/03, Traghetti del Mediterraneo, ECLI:EU:C:2006:391, Rec. p. 5177. 
ha brindado el contencioso del conocido como del «céntimo sanitario». Como es sabido, el Tribunal de Justicia de la Unión Europea dictó Sentencia en febrero de 2014 por la que se declaraba que el Impuesto sobre las Ventas Minoristas de Determinados Hidrocarburos es contrario al artículo 3, apartado 2, de la Directiva 92/12/CEE del Consejo, de 25 de febrero de 1992, relativa al régimen general, tenencia, circulación y controles de los productos objeto de impuestos especiales, «ya que no puede considerarse que tal impuesto persiga una finalidad especifica en el sentido de dicha disposición, toda vez que el mencionado impuesto, destinado a financiar el ejercicio, por parte de los entes territoriales interesados, de sus competencias en materia de sanidad y de medioambiente, no tiene por objeto, por sí mismo, garantizar la protección de la salud y del medioambiente» ${ }^{22}$. En dicha sentencia, el Tribunal no admitió la petición formulada por la Generalitat de Catalunya y el Gobierno español en el sentido de limitar los efectos retroactivos de la misma. Invocaban al efecto las repercusiones económicas graves que tendría una sentencia que realice dicha declaración de ilegalidad, dado que el Impuesto alcanzó un rendimiento de alrededor de trece mil millones de euros entre 2002 y 2011, según las propias Administraciones (apartado 38 de la Sentencia).

La consecuencia de la declaración de incompatibilidad de la normativa española con la Directiva es la obligación de devolución de lo indebidamente cobrado. Sin embargo, para que tal devolución se lleve a cabo, se exige, con toda lógica, la presentación por parte de los afectados de documentación que permita demostrar el pago de tales recargos. En la práctica es obvio que, en el caso de los particulares, la posibilidad de que hayan guardado tal documentación es muy escasa, por no decir nula. Pero incluso en el de los profesionales parece que la recuperación no sería sencilla ${ }^{23}$. Resulta claro que el incumplimiento del Derecho de la Unión en el que ha incurrido el Estado le ha resultado a éste altamente rentable y que, a la postre, el ordenamiento de la UE tiene dificultades para desplegar todos sus efectos beneficiosos en favor de sus destinatarios finales.

${ }^{22}$ Sentencia del TJUE de 27 de febrero de 2014, asunto C-82/12, Transportes Jordi Besora, S.L., ECLI:EU:C:2014:108, todavía no publicada en el Repertorio. Se puede consultar el texto en: $<$ http://curia.europa.eu/juris/document/document.jsf?text=\&docid= 148383\&pageIndex $=0 \&$ doclang $=$ es \&mode $=$ req \& dir=\&occ=first\&part $=1 \&$ cid $=125913>$ (última consulta: 30 de octubre de 2014).

${ }^{23}$ En la rueda de prensa que ofreció el Ministro de Hacienda y Administraciones Públicas el 30 de septiembre de 2014, afirmó que la cantidad destinada en los presupuestos de 2015 a tal devolución ascendería a 2.000 millones de euros, si bien parece que la cantidad final se acercaría más a los 2.500. De hecho, el 13 de noviembre de 2014 el Ministerio de Hacienda y el Comité Nacional del Transporte por Carretera alcanzaron acuerdo que supondría elevar la cantidad devuelta hasta esos 2.500 millones citados. 


\section{BIBLIOGRAFÍA}

Ballugera Gómez, C., «Integración de cláusulas declaradas nulas por abusivas: visión general», Diario La Ley, n. ${ }^{\circ}$ 8330, Sección Doctrina, 1 de Julio de 2014.

Canedo Arrillaga, J. R.; Gordillo Pérez, L. I., «Tutela judicial, autonomía procedimental y efectividad del Derecho de la Unión», Revista General de Derecho Constitucional, n. ${ }^{\circ} 15,2012$.

Clavería GosÁlBez, L. H., «La progresiva degradación de nuestro ordenamiento en materia de cláusulas contractuales abusivas», Revista Aranzadi Doctrinal, n. ${ }^{\circ} 5$, 2014, pp. 29-42.

Córdoba CASTROVERDE, D., «¿Cumple nuestro ordenamiento los requisitos exigidos por la sentencia Köbler?», Civitas. Revista Española de Derecho Europeo, n. 37 , 2011, pp. 7-36.

Estrada Alonso, E.; Fernández Chacón, I., «Ejecución hipotecaria y cláusulas abusivas (A propósito de la cuestión prejudicial planteada en el asunto «Mohamed Aziz» c. Catalunya-caixa)», Revista Crítica de Derecho Inmobiliario, año n. ${ }^{\circ} 89$, n. $^{\circ} 735,2013$, pp. 173-244.

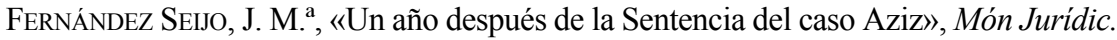
Revista de l'il.lustre col.legi d'advocats de barcelona, n. ${ }^{\circ} 286$, abril 2014, pp. 16-17.

Gómez de Liaño Fonseca Herrero, M., «El control de oficio de las cláusulas abusivas. El juez nacional como garante de la protección del consumidor», Revista de Derecho de la Unión Europea, n. ${ }^{\circ}$ 26, 2014, pp. 313-328.

GonzÁlez ClaviJo, J. R., «Comentarios sobre la sentencia del Tribunal de Justicia de la Unión Europea (Sala primera) de 14 de marzo de 2013 (asunto C-415/11, Mohamed Aziz-Catalunyacaixa)», Revista General de Derecho Europeo, n. ${ }^{\circ} 30$, mayo 2013.

GoÑI Rodríguez de AlmeIdA, M., «El procedimiento de ejecución de bienes hipotecados cuando existen cláusulas abusivas en el préstamo hipotecario que lo originó: consecuencias de la STJUE 14 marzo de 2003 y de la Ley 1/2013, de 14 de mayo, de medidas para reforzar la protección a los deudores hipotecarios, reestructuración de deuda y alquiler social», Revista Crítica de Derecho Inmobilia-

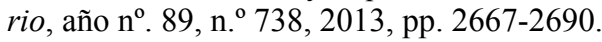

IgLESIAS SÁNCHEZ, S., "Unfair terms in mortgage loans and protection of housing in times of economic crisis: Aziz v. Catalunyacaixa - Case C-415/11, Mohamed Aziz v. Catalunyacaixa, Judgment of the Court of Justice (First Chamber) of 14 March 2013», Common Market Law Review, Vol. 51, n. ${ }^{\circ} 3$, 2014, pp. 955-974.

Lo Schiavo, G., «Droit européen de la consommation (arrêt «Aziz»)», Revue du droit de l'Union Européenne, n. ${ }^{\circ}$ 2, 2013, pp. 359-365.

MARTínez Espín, P., «¿Qué hay de nuevo en materia de cláusulas abusivas?», Revista CESCO de Derecho de Consumo, n. ${ }^{\circ}$ 9, 2014, pp. 76-84.

PASCUAL SERRATS, R., «El recurso por responsabilidad extracontractual», en El sistema jurisdiccional de la Unión Europea, coord. por Virginia Pardo Iranzo, José Luis Iglesias Buhigues, Juan Montero Aroca, 2013, pp. 155-172.

Pazos CAstro, R., «El control de las cláusulas abusivas y la autonomía de la voluntad del consumidor ante el juez (comentario a la STJUE de 30 de mayo de 2013, Asbeek Brusse y De Man Garabito)», Boletín del Ministerio de Justicia, año 68, n. ${ }^{\circ} 2162,2014$, pp. 1-17. 
Poiares Maduro, M.; Azoulai, L. (eds.), The Past and the Future of EU Law, Hart Publishing, Oxford, 2010.

RobIN-OliviER, S., "The evolution of direct effect in the EU: Stocktaking, problems, projections», International Journal of Constitutional Law, vol. 12, n. ${ }^{\circ}$ 1, 2014, pp. 165-188.

SÁNCHEZ GonzÁLEZ, M. P., «Tribunal de Justicia de la Unión Europea - TJUE - Sentencia de 14.03.2013, Mohamed Aziz, C-415/11 - «Directiva 93/13/CEE - Contratos celebrados con consumidores - Préstamo hipotecario - Procedimiento de ejecución hipotecaria - Facultades del juez nacional - Cláusulas abusivas» - Incidencia del carácter abusivo de una cláusula contractual sobre el procedimiento de ejecución hipotecaria», Revista de Derecho Comunitario Europeo, año n. ${ }^{\circ} 17$, $n^{\circ} 44,2013$, pp. 327-344.

SCHERR, K. M., «Comparative aspects of the application of the principle of State liability for judicial breaches», ERA Forum, marzo 2012, Vol. 12, n. ${ }^{\circ} 4$, pp. 565-588.

WARD, A., Judicial Review and the Rights of Private Parties in EU Law, 2. a edición, OUP, 2007.

TITLE: Problems of effectiveness of EU law. The area of unfair terms as test bench.

RESUMEN: Pese al profundo alcance que algunas normas del ordenamiento jurídico de la Unión Europea (UE) buscar conseguir, la aplicación que por parte de los tribunales internos se hace de las mismas no siempre se ajusta al fin perseguido. Por otro lado, existen situaciones en las que el propio ordenamiento europeo no es capaz de asegurar la protección buscada para los particulares, especialmente en conflictos contra empresas o contra el propio Estado.

PALABRAS CLAVE: Cláusulas abusivas, Intereses moratorios, Aplicación interna del Derecho UE, Valor de la jurisprudencia del TJUE, reclamación de daños y perjuicios por incumplimiento del Derecho UE.

ABSTRACT: Despite the deep reach some pieces of the European Union legal order legal try to reach, their application by domestic courts does not always achieve the aim pursued. On the other hand, there are situations in which the European legal order itself is not able to ensure the protection sought for individuals, especially in disputes against companies or against the State itself.

KEYWORDS: Unfair terms, Interests on late payments, Internal application of EU law, Value of the CJEU case law, Member states liability for breach of EU law. 